\title{
Germination Characteristics and
}

\section{Chemical Control of Horehound}

\section{J. F. STRITZKE}

Highlight: Less than 35\% of the seed collected in October from mature plants of horehound (Marrubium vulgare L.) would germinate. Seventy-eight percent of the seeds germinated after 1 month of wet storage at $0^{\circ} \mathrm{C}$. From 20 to $25 \%$ of the seeds were still dormant after 4 months of storage at the three conditions tested. Better than $90 \%$ control of the existing horehound plants was possible with both 2,4-D and silvex at a rate of $2 \mathrm{lb} / \mathrm{acre}$.

Horehound (Marrubium vulgare L.) is an introduced perennial forb from Britain that reproduces by rhizomes and seeds. It belongs to the mint family and is recognized easily with its square stem, opposite roundish serrate leaves, and white fuzzy stem (Fig. 1). The seeds of the plant are formed in tubular spiny-hooked calyxes (Fig. 2) and these frequently catch in the wool of sheep; thus, lowering the value of the wool, as well as helping in the scattering of the plant. It is thought to have escaped from cultivation in California in 1833 (Ridley, 1930). Since that time, it has become widely distributed throughout the regions where sheep are raised. It is found growing primarily in fence lines surrounding corral areas, but is becoming naturalized and spreading into adjacent open range areas. The leaves and flower stalks are used in the preparation of certain cough medicines and for flavoring candy. The pharmaceutical value of the plant is due to marrubiin (a bitter substance from the flowering stem), and it has been used in the treatment of fever, asthma, and snake bites. Sterol and sesquiterpenes have also been isolated from plant extracts (Nicholas, 1964). The plants flower early in the spring and are used readily by bees as a source of nectar (Wells, 1956).

There have been attempts to use the plant as a forage plant (Dean, 1957), but the characteristic bitter taste of the plant makes it undesirable

The author is assistant professor, Department of Agronomy, Oklahoma State University, Stillwater.

Journal Article 2889 of the Agricultural Experiment Station, Stillwater, Okla.

Manuscript received July 8, 1974. to animals.

The objective of this study was to find ways to control horehound and to determine the dormancy condition of the seeds.

\section{Materials and Methods}

A horehound infestation on Ted Webb's ranch of Custer, Okla., was utilized for these studies. Sheep had been kept on the ranch in previous years, and a solid infestation of horehound was present in the fence rows and areas surrounding the old pens. Various herbicides were evaluated in 1972 and 1973 (see Table

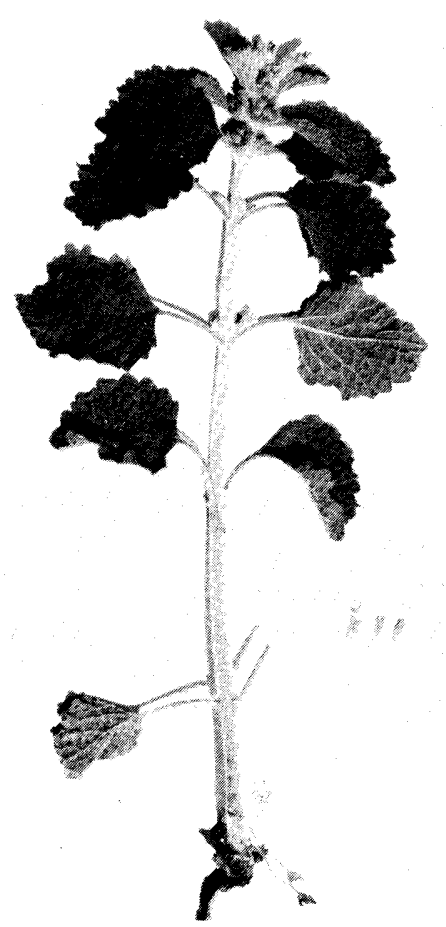

Fig. 1. Horehound stem as seen in May during flowering. Also, three detached flowers are shown to the right of the plant stem.
1 and 2 for herbicides and rates). In both years, plot size was $10 \times 20$ feet. Each treatment was replicated four times. Herbicide treatments were applied with a small portable $\mathrm{CO}_{2}$ sprayer at 25 gpa of water. The percent of plants killed was determined in the fall after spraying. The control of the established plants in the 1972 study was also evaluted one year after application.

In the fall of 1973 (October 25), seeds were collected from mature plants in the fence rows and placed at various temperatures $(10,14,18,22$, $\left.26,30^{\circ} \mathrm{C}\right)$ to determine viability and dormancy of the seeds. The dormancy of the seeds was evaluated further by dividing the seed into 3 groups and placing in different environmental conditions $\quad\left(22^{\circ} \mathrm{C}\right.$-dry, $\quad 0^{\circ} \mathrm{C}$-dry, $0^{\circ} \mathrm{C}$-moist). The germination was checked monthly for 4 months by placing a group of seeds in germination containers at $26^{\circ} \mathrm{C}$.

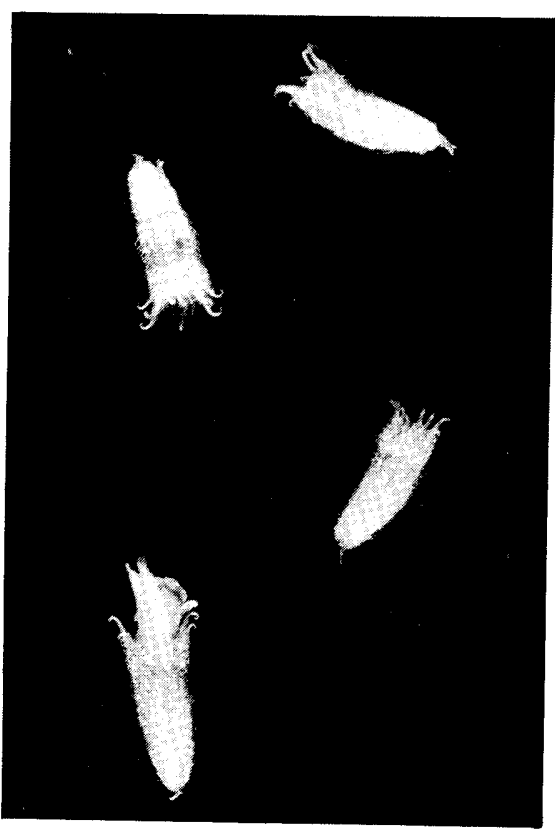

Fig. 2. Four flowers as seen in May. The white petals are still evident on one of the flowers and the spiny-hooked teeth of the calyx are evident on all of the flowers. Four seeds are formed within each calyx. These spiny-hooked calyxes which are about 1/4-inch long catch in the wool of sheep. 
